\title{
Public Pension, Capital Stock and Consumption in Rural China
}

\author{
Zaigui Yang \\ $\mathrm{PhD}$, Professor at China Institute for Actuarial Science \\ Central University of Finance and Economics. \\ Yuan Cao \\ doctorial student at School of Insurance \\ Central University of Finance and Economics
}

\begin{abstract}
This paper investigates the rural public pension in China by employing an overlappinggenerations model. We examine the effects of the individual contribution rate, village subsidy rate, local government allowance rate, basic pension benefit rate and population growth rate on the capital-labor ratio, per capita consumption and pension benefits. Raising the individual contribution rate only increases the per capita pension benefits, and has no effect on the capital-labor ratio and per capita consumption. Raising both the village subsidy rate and local government allowance rate increases the capital-labor ratio, per capita consumption and pension benefits. Raising the basic benefit rate decreases the capital-labor ratio and per capita consumption, while increases the pension benefits. $A$ rise in the population growth rate decreases the capital-labor ratio, per capita consumption, and pension benefits. In accordance with the effects and their intensities, it will do more good than harm to raise the individual contribution rate and village subsidy rate, maintain the present basic benefit rate and accordingly raise the local government allowance rate by adjusting the structure of fiscal expenditures, and control the population growth rate.
\end{abstract}

Keywords: rural public pension; capital stock; consumption

\section{INTRODUCTION}

The "State Council Guidance on New Type Rural Public Pension Pilots" (Chinese State Council Document 32 in 2009) stipulates: Peasants make pension contributions, villages subsidize and local governments allowance the individual contributions. Individual contribution standards include five levels, 100, 200, 300, 400 and 500 Yuan per participant per year. Peasants can choose one of the levels as they like. Villages subsidize the individual contributions according to the decision of villagers' meeting. Local governments allowance the individual contributions with a standard not less than 30 Yuan per participant per year. The individual contributions, village subsidies and local government allowances are accumulated in the peasants' individual accounts. Each retiree (peasant above the age of 60) can draw individual account benefits from her/his individual account and get basic pension benefits from the central government and local government. The central government pays full basic benefits decided by the central government to the retired peasants in western and central areas, and a half of that to those in eastern areas (this is not explained explicitly, maybe it is because the later is richer than the former). The full basic benefits decided by the central government are 55 Yuan per retiree per month. Local governments can pay more basic benefits to retired peasants according to local circumstances. The rural public pension system is expected to reduce rural poverty, narrow the gaps between urban and rural areas, and promote domestic consumption. 
However, the present rural public pension has the following problems: the pension benefits are very low; most participants choose the lowest pension contribution grade; the village subsidies and local government allowances are also very low; and the incentive mechanism is inefficient. In addition, village collective economy offers less competitive products and declines with the upgrading and adjustment of national industrial structure. Hence, it is difficult for villages to subsidize individual contributions and to provide sufficient incentives for participants to choose higher contribution level. Although there are additional subsidy policies on basic pension benefits, the power of these policies is small. These problems, such as insufficient village subsidies and local government allowances, as well as lack of significant incentive mechanism for the long-term participants, will eventually impede the sustainable development of the rural pension system. Therefore, the new system should strengthen incentive mechanism, and gradually upgrade the financing ability and pension benefit level.

Research on the rural public pension should take into account the concrete situations in China. Firstly, the pension benefit level should be raised. The per capita annual net income of rural residents is 7916.6 Yuan. The basic pension benefits are 55 Yuan per month, which only provides the replacement rate of $8.3 \%$. Secondly, world economy has been recovering slowly after the international financial crisis. China's economy is also affected. The growth rate has come down significantly in the last two years, and the downside pressure remains. Although the quality and efficiency of economic development have got unparalleled attention now, the economic growth should not be ignored, because it affects employment, income and social stability. It relies on expanding domestic demand, including consumption demand and investment demand, to maintain the stable, sustainable and healthy growth of China's economy after the financial crisis. Finally, although China is implementing new population policy which allows two children per family if husband or wife is a single child in their own families before getting married, the new policy is unlikely to result in dramatic increase in the rural population growth rate.

Overlapping-generations (OLG) model has been used widely in the literature to investigate the relationship between public pension system and consumption and capital stock. Barro (1974) argues that if individuals in successive generations were linked by bequests, changes in the stock of government debt or in social security programs would have no effect on the steady state capital stock. Feldstein (1974) uses an extended life-cycle model to analyze the impact of social security on the individual's simultaneous decision about retirement and saving, and concludes that social security would reduce the capital-labor ratio in models that do not admit a bequest motive. Blanchard and Fischer (1989) use the OLG model to study PAYG and fully funded social security system. It is shown that a PAYG social security system prevents the rate of capital accumulation and reduces the steady state capital stock. A fully funded social security system has no effect on total savings and capital accumulation. The reason is that the increase in social security savings is exactly offset by a decrease in private savings in such a way that the sum of the two is equal to the previous level of private savings. Zhang and Zhang (1998) analyze the effects of social security on savings, fertility, and per capita income growth with three specifications of utility functions. The literature studies PAYG or fully funded public pensions based on developed countries.

There is also some domestic literature to study the public pension system for urban enterprise employees in China with OLG model. Wang et al., (2001) use computable general equilibrium model to examine the impacts of various design options for pension system reform on the sustainability of the system and on overall economy growth. Within a framework of an endogenous growth OLG model, Yang (2009) examines the effects of the public pension system 
on the fertility, economic growth and family old-age security. Kang (2012) compares the effects of improving the contribution rate and postponing the retirement age on capital stock per worker, personal and social pooling account pension level and other economic variables within a general equilibrium OLG model. However, what the literature study is the basic pension system for enterprise employees in China. It is hard to find the studies regarding on the rural public pension system. Employing an endogenous growth model, Yang (2011) investigates the rural public pension by examining the effects of the individual contribution rate, village subsidy rate, local government allowance rate and basic benefit rate on the labor income growth rate, population growth rate, consumption rate, saving rate and education expense rate. But the model is an endogenous growth model. In this paper, we aim to establish an exogenous OLG model to study the rural public pension.

According to the literature mentioned above and the reality of rural public pension, we develop an exogenous overlapping-generations model, examine whether and how the individual contribution rate, village subsidy rate, local government allowance rate, basic pension benefit rate and population growth rate affect the capital-labor ratio, per capita consumption and pension benefits. We estimate relevant parameter values according to the actual situation in the rural areas, and simulate the effects and their strengths. We hope to look for suitable policies to enhance the local government allowances and village subsidies, raise the individual contribution level and pension benefit level, and promote domestic consumption and capital stock. Most of the studies are based on the assumption that only individual participant pays pension contributions. The exogenous OLG model in this paper considers not only the individual contributions, but also the village subsidies and local government allowances.

\section{THE MODEL}

This paper adopts Diamond's (1965) two-period OLG model. There are numerous individuals and villages and a government in a closed economy. Each individual lives for two periods: working period and retirement period. At the beginning of period $\mathrm{t}$, Nt identical individuals of generation t enter the workforce. The population grows at a rate of $n=(\mathrm{Nt} / \mathrm{Nt}-1)-1$.

\section{Individuals}

In working period each individual earns wage by supplying inelastically one unit of labor, makes pension contributions, consumes part of her income, and saves the remainder of the income. In retirement period, she consumes her savings with accrued interest, individual account benefits and basic pension benefits. Each individual derives utility from the workingperiod consumption and retirement-period consumption. The utility is described by a logarithmic function. Each individual maximizes her utility by choosing savings and consumption. Hence, the utility maximization problem is:

$$
\begin{aligned}
& \max _{\left\{s_{t}, C_{1, t}, C_{2, t+1}\right\}} U_{t}=\ln c_{1, t}+\theta \ln c_{2, t+1}, \\
& \text { s.t. } \quad c_{1, t}=(1-\tau) w_{t}-s_{t}, \\
& c_{2, t+1}=\left(1+r_{t+1}\right) s_{t}+I_{t+1}+J_{t+1},
\end{aligned}
$$

where $q \hat{I}(0,1)$ denotes the individual discount factor, $t \hat{I}(0,1)$ the individual contribution rate, wt the wage, st the savings, $r t+1$ the interest rate, It +1 the individual account benefits, Jt+1 the basic pension benefits. The first-order condition is:

$$
\theta\left(1+r_{t+1}\right) c_{1, t}=c_{2, t+1} \text {, }
$$


This equation implies that the utility loss from reducing one unit of working-period consumption is equal to the utility gain from increasing $(1+r t+1)$ units of retirement-period consumption.

\section{Villages}

Villages produce homogenous commodities in competitive markets. The production is described by Cobb-Douglas function $Y_{t}=A K_{t}^{\alpha} N_{t}^{1-\alpha}$ or $y_{t}=A k_{t}^{\alpha}$, where $Y_{t}$ is the output in period t, $K_{t}$ the capital stock, $a \in(0,1)$ the capital share of income, $A$ the productivity, $y_{t}$ the output-labor ratio and $k_{t}=K_{t} / N_{t}$ the capital-labor ratio.

Based on the total labor income, villages provide pension contribution subsidies at a rate of $\eta$ $\in(0,1)$, the local government allowance rate is $\zeta \in(0,1)$, and the basic pension benefit rate is $j$ $\in(0,1)$. In the long term, the village subsidies, local government allowances and basic pension benefits paid by the central government and local governments together are all from the peasants' achievement, which is a part of the labor income. According to the product distribution, we can get that $A K_{t}^{\alpha} N_{t}^{1-\alpha}=r_{t} K_{t}+(1+\eta+\zeta+j) N_{t} w_{t}$. By virtue of Euler's theorem, we have:

$$
\begin{array}{r}
r_{t}=\alpha A k_{t}^{\alpha-1}, \\
w_{t}=\frac{(1-\alpha) A k_{t}^{\alpha}}{1+\eta+\zeta+j} .
\end{array}
$$

\section{The government}

The individual pension contributions, village subsidies and local government allowances are saved in the individual accounts by governments. The accumulation in the individual account is used to pay the individual when she/he retires in the next period:

$$
I_{t+1}=\left(1+r_{t+1}\right)(\tau+\eta+\zeta) w_{t}
$$

Based on the total labor income of working generation, the governments pay the basic pension benefits to retirees at the basic pension benefit rate: $N_{t-1} J_{t}=j N_{t} w_{t}$, or

$$
J_{t}=(1+n) j w_{t} \text {. }
$$

\section{Dynamic Equilibrium}

Substituting equations (2), (3) and (5) - (9) into equation (4) gives the following dynamic equilibrium system:

$$
k_{t}^{\alpha}=\frac{(1+\eta+\zeta+j)(1+\theta)(1+n)}{\theta(1+\eta+\zeta)(1-\alpha) A} k_{t+1}+\frac{(1+n) j k_{t+1}^{\alpha}}{\theta(1+\eta+\zeta)\left(1+A \alpha k_{t+1}^{\alpha-1}\right)}
$$

Assume that there is unique, stable and nonoscillatory steady state equilibrium. In order to find the stability condition, we linearize Dynamic System (10) around the steady-state (k) gives

$$
p\left(k_{t+1}-k\right)+q\left(k_{t}-k\right)=0 \text {, }
$$

where

$$
p=-\frac{(1+\eta+\zeta+j)(1+\theta)(1+n)}{\theta(1+\eta+\zeta)(1-\alpha) A}-\frac{(1+n) j \alpha k^{\alpha-1}\left(1+A k^{\alpha-1}\right)}{\theta(1+\eta+\zeta)\left(1+A \alpha k^{\alpha-1}\right)^{2}}<0
$$




$$
q=\alpha k^{\alpha-1}>0
$$

The assumption that the equilibrium is unique, stable and nonoscillatory implies $0<\frac{k_{t+1}-k}{k_{t}-k}=-\frac{q}{p}<1$, Therefore, the stability condition is

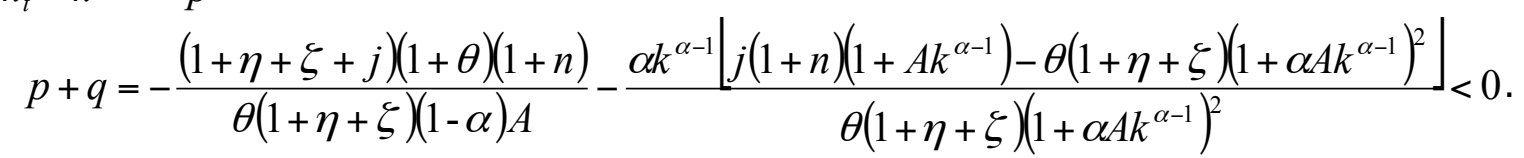

\section{COMPARATIVE STATICS}

Since the individual contributions (compulsory savings) crowd-out the voluntary savings, the individual contribution rate did not appear in equation (10) and has no effect on the capitallabor ratio. Totally differentiating equation (10) around the steady state gives

$$
(p+q) d k+m d \eta+g d \zeta+h d j+l d n=0,
$$

where

$$
\begin{gathered}
m=\frac{(1+\theta)(1+n) j}{\theta(1-\alpha) A(1+\eta+\zeta)^{2}} k+\frac{(1+n) j k^{\alpha}}{\theta(1+\eta+\zeta)^{2}\left(1+A \alpha k^{\alpha-1}\right)}>0 \\
g=\frac{(1+\theta)(1+n) j}{\theta(1-\alpha) A(1+\eta+\zeta)^{2}} k+\frac{(1+n) j k^{\alpha}}{\theta(1+\eta+\zeta)^{2}\left(1+A \alpha k^{\alpha-1}\right)}>0 \\
h=-\frac{(1+\theta)(1+n)}{\theta(1+\eta+\zeta)(1-\alpha) A} k-\frac{(1+n) k^{\alpha}}{\theta(1+\eta+\zeta)\left(1+A \alpha k^{\alpha-1}\right)}<0 \\
l=-\frac{(1+\theta)(1+\eta+\zeta+j)}{\theta(1+\eta+\zeta)(1-\alpha) A} k-\frac{j k^{\alpha}}{\theta(1+\eta+\zeta)\left(1+A \alpha k^{\alpha-1}\right)}<0 .
\end{gathered}
$$

Define $c_{t}=\frac{N_{t} c_{1 t}+N_{t-1} c_{2 t}}{N_{t}}=c_{1 t}+\frac{c_{2 t}}{1+n}$ as per capita consumption, $B_{t}=I_{t}+J_{t}$ as pension benefits per retiree. When the economy converges to the steady state equilibrium, the per capita consumption and pension benefits become:

$$
\begin{gathered}
c=A k^{\alpha}-n k, \\
B=\left[\left(1+\alpha A k^{\alpha-1}\right)(\tau+\eta+\zeta)+(1+n) j\right] \frac{(1-\alpha) A k^{\alpha}}{1+\eta+\zeta+j} .
\end{gathered}
$$

\section{Effect of individual contribution rate}

The individual contribution rate has no effect on the capital-labor ratio, i.e. $\partial k / \partial \tau=0$. Partially differentiating $c$ and $B$ with respect to $\tau$, gives:

$$
\begin{gathered}
\frac{\partial c}{\partial \tau}=0 \\
\frac{\partial B}{\partial \tau}=\left(1+\alpha A k^{\alpha-1}\right) \frac{(1-\alpha) A k^{\alpha}}{1+\eta+\zeta+j}>0 .
\end{gathered}
$$

According to equation (12), individual contribution rate has no effect on the capital-labor ratio, thus has no effect on per capita consumption. The pension benefits are composed of the individual account benefits and basic pension benefits, hence a rise in the individual contribution rate increases the individual account pension, and furthermore the pension benefits. 


\section{Effect of village subsidy rate and local government allowance rate}

Partially differentiating $k, c$ and $B$ with respect to $\eta$, gives:

$$
\begin{gathered}
\frac{\partial k}{\partial \eta}=-\frac{m}{p+q}>0, \\
\frac{\partial c}{\partial \eta}=\left(A \alpha k^{\alpha-1}-n\right) \frac{\partial k}{\partial \eta}, \\
\frac{\partial B}{\partial \eta}=(1-\alpha) \frac{\alpha A k^{\alpha-1}}{(1+\eta+\zeta+j)} \frac{\partial k}{\partial \eta}\left[(\tau+\eta+\zeta)\left(1+(2 \alpha-1) A k^{\alpha-1}\right)+(1+n) j\right] \\
+(1-\alpha) \frac{A k^{\alpha}}{(1+\eta+\zeta+j)^{2}}\left[\left(1+\alpha A k^{\alpha-1}\right)(1+j-\tau)-(1+n) j\right]
\end{gathered}
$$

Raising the village subsidy rate increases the capital-labor ratio. According to equation (9), raising the village subsidy rate increases capital-labor ratio directly, and decreases labor income indirectly. The direct effect is greater than the indirect effect, thus raising the village subsidy rate increases the capital-labor ratio. When $A \alpha k^{\alpha-1}>n$, according to equation (12), raising the village subsidy increases per capita consumption. According to equation (13), raising the village subsidy rate decreases the labor income and increases the individual account benefits directly, increases the capital-labor ratio and decreases the interest rate indirectly. Hence, the overall effect of village subsidy rate on the pension benefits is ambiguous.

According to equations (10) - (11) and the expressions of $m$ and $g$, the effect and function of $\zeta$ and $\eta$ in the model are consistent. So the effects of the local government allowance rate on $k, c$ and $B$ are as the same as that of the village subsidy rate. That is, raising the local government allowance rate increases the capital-labor ratio, and increases per capita consumption if the interest rate is higher than the population growth rate, but the effect on the pension benefits cannot be determined.

\section{Effect of basic pension benefit rate}

Partially differentiating $k, c$ and $B$ with respect to $j$, gives:

$$
\begin{gathered}
\frac{\partial k}{\partial j}=-\frac{h}{p+q}<0 \\
\frac{\partial c}{\partial j}=\left(A \alpha k^{\alpha-1}-n\right) \frac{\partial k}{\partial j} \\
\frac{\partial B}{\partial j}=(1-\alpha) \frac{A k^{\alpha-1}}{(1+\eta+\zeta+j)}\left[\alpha(\tau+\eta+\zeta)\left[1+(2 \alpha-1) A k^{\alpha-1}\right] \frac{\partial k}{\partial j}+(1+n)\left(k+j \alpha \frac{\partial k}{\partial j}\right)\right] . \\
-(1-\alpha) \frac{A k^{\alpha}}{(1+\eta+\zeta+j)^{2}}\left[(\tau+\eta+\zeta)\left(1+\alpha A k^{\alpha-1}\right)+(1+n) j\right]
\end{gathered}
$$

Raising the basic pension benefit rate decreases the capital-labor ratio. A rise in the basic pension benefit rate decreases the labor income and voluntary savings, and both of which decrease the capital-labor ratio. According to equation (12), raising the basic pension benefit rate decreases per capita consumption if the interest rate is higher than the population growth 
rate. According to equation (13), raising the basic pension benefit rate has a positive impact on the basic pension benefits, and decreases the labor income directly, decreases the capital-labor ratio indirectly and increases the interest rate. The overall effect of the basic pension benefit rate on the pension benefits is ambiguous.

\section{Effect of population growth rate}

Partially differentiating $k, c$ and $B$ with respect to $n$, gives:

$$
\begin{gathered}
\frac{\partial k}{\partial n}=-\frac{l}{p+q}<0 \\
\frac{\partial c}{\partial n}=\left(\alpha A k^{\alpha-1}-n\right) \frac{\partial k}{\partial n}-k \\
\frac{\partial B}{\partial n}=\frac{\left.(1-\alpha) \alpha A k^{\alpha-1}\left\{1+(2 \alpha-1) A k^{\alpha-1}\right)(\tau+\eta+\zeta)+(1+n) j\right\}}{1+\eta+\zeta+j} \frac{\partial k}{\partial n}+j \frac{(1-\alpha) A k^{\alpha}}{1+\eta+\zeta+j} .
\end{gathered}
$$

A rise in the population growth rate decreases the capital-labor ratio because of the dilution effect of population growth. According to equation (12), a rise in the population growth rate decreases the per capita consumption if the interest rate is higher than the population growth rate. According to equation (13), a rise in the population growth rate decreases the capitallabor ratio and labor income indirectly, increases the interest rate and has a positive impact on the basic pension benefits. The overall effect of the population growth rate on the pension benefits cannot be determined. Since some effects of the exogenous variables on the endogenous variables cannot be determined, we check the effects by simulations below.

\section{Parameter setting}

\section{NUMERICAL EXPERIMENT}

Because one period is usually assumed to be 25 - 30 years in OLG model, and the data of National Population Census in 1982 and 2010 are used in this model, we set each period as 28 years in this paper. The individual discount factor per year is assumed to be 0.985 , which is similar to that used by Pecchenino and Pollard (2002). Hence, the individual discount factor per period is $\theta=0.985^{28}$.

The capital share of income is usually estimated as 0.3 in developed countries (e.g., Zhang et al., 2001; Pecchenino and Pollard, 2002). The labor in China is comparatively cheaper, thus the labor share of income is lower, while the capital share of income is higher than that in developed countries. Hence, we assume that $\alpha$ in China could be 0.35 . Since the technological progress is not reflected in this model, and what we want to see here is how the endogenous variables change with the exogenous variables, the constant $A$ can be normalized as 1 .

According to China Statistical Yearbook, the rural employed population growth rate in the period from 1984 to 2012 is computed to be $n=39602 / 35968-1$. The rural public pension came out in 2009. But the peasants above the age of 60 have gotten pension benefits because they had contributed to the pension system when they were young through price scissors of industrial and agricultural products, agriculture taxes, etc.

At present, the annual contributions per participant are 183 Yuan and the monthly pension benefits per retiree 82 Yuan (Gao, 2013). Calculated with 7916.6 Yuan of net annual income per capita in rural areas, the individual contribution rate is computed to be $\tau=183 / 7916.6$. According to the annual pension benefits per retiree $J=12 \times 82$ Yuan and equation (8), the basic pension benefit rate is computed to be $j=J /[(1+n) w] \approx 11.289 \%$. The State Council Document 
32 in 2009 stipulates: Local government allowances participant no less than 30 Yuan per person per year; village subsidy standards should be democratically determined by villagers' committee. Because the allowances in different regions are different and there is no authorized data, we assume the local government allowances to each participant per year are 45 Yuan. Thus, the local government allowance rate is $\zeta=45 / 7916.6$. The village subsidies are lower than the local government allowances, thereby we assume the subsidies are 30 Yuan per participant per year, hence the village subsidy rate is $\eta=30 / 7916.6$. These are benchmark values of the parameters.

\section{Simulation}

Other things are equal, raising the individual contribution rate gradually to $7.0 \%$, simulating with them gives the result shown in Table 1.0bviously, raising the individual contribution rate only increases the pension benefits, and has no effect on the capital-labor ratio and per capita consumption.

Table 1 the effect of $\tau$ on $k, c, B$

\begin{tabular}{cccccc}
\hline$\tau$ & $2.3 \%$ & $4.0 \%$ & $5.0 \%$ & $6.0 \%$ & $7.0 \%$ \\
\hline$k$ & 0.0815 & 0.0815 & 0.0815 & 0.0815 & 0.0815 \\
$c$ & 0.4075 & 0.4075 & 0.4075 & 0.4075 & 0.4075 \\
$B$ & 0.0518 & 0.0631 & 0.0698 & 0.0765 & 0.0832 \\
\hline
\end{tabular}

Other things are equal, raising the village subsidy rate gradually to $2.0 \%$, simulating with them gives the result shown in Table 2 . Raising the village subsidy rate increases the capital-labor ratio, per capita consumption and pension benefits.

Table 2 Table 1 the effect of $\eta$ on $k, c, B$

\begin{tabular}{cccccc}
\hline$\eta$ & $0.4 \%$ & $0.7 \%$ & $1.0 \%$ & $1.5 \%$ & $2.0 \%$ \\
\hline$k$ & 0.0815 & 0.0815 & 0.0816 & 0.0817 & 0.0818 \\
$c$ & 0.4075 & 0.4077 & 0.4078 & 0.4079 & 0.4081 \\
$B$ & 0.0518 & 0.0538 & 0.0557 & 0.0588 & 0.0618 \\
\hline
\end{tabular}

Other things are equal, raising the local government allowance rate gradually to $2.5 \%$, simulating with them gives the result shown in Table 3. Raising the local government allowance rate increases the capital-labor ratio, per capita consumption and pension benefits.

Table 3 Table 1 the effect of $\zeta$ on $k, c, B$

\begin{tabular}{cccccc}
\hline$\zeta$ & $0.568 \%$ & $1.0 \%$ & $1.5 \%$ & $2.0 \%$ & $2.5 \%$ \\
\hline$k$ & 0.0815 & 0.0816 & 0.0817 & 0.0818 & 0.0819 \\
$c$ & 0.4075 & 0.4077 & 0.4079 & 0.4080 & 0.4082 \\
$B$ & 0.0518 & 0.0545 & 0.0576 & 0.0607 & 0.0637 \\
\hline
\end{tabular}

Other things are equal, raising the basic pension benefit rate gradually to $20.0 \%$, simulating with them gives the result shown in Table 4. Raising the basic pension benefit rate decreases the capital-labor ratio and per capita consumption, while increases the pension benefits. 
Table 4 Table 1 the effect of $j$ on $k, c, B$

\begin{tabular}{llllll}
\hline$j$ & $11.3 \%$ & $14.0 \%$ & $16.0 \%$ & $18.0 \%$ & $20.0 \%$ \\
\hline$k$ & 0.0815 & 0.0767 & 0.0735 & 0.0704 & 0.0675 \\
$c$ & 0.4075 & 0.3994 & 0.3936 & 0.3879 & 0.3825 \\
$B$ & 0.0518 & 0.0569 & 0.0604 & 0.0636 & 0.0667 \\
\hline
\end{tabular}

Other things are equal, raising the population growth rate gradually to $18.0 \%$, simulating with them gives the result shown in Table 5. A rise in the population growth rate decreases the capital-labor ratio, per capita consumption and pension benefits.

Table 5 Table 1 the effect of $n$ on $k, c, B$

\begin{tabular}{cccccc}
\hline$n$ & $10.1 \%$ & $12.0 \%$ & $14.0 \%$ & $16.0 \%$ & $18.0 \%$ \\
\hline$k$ & 0.0815 & 0.0797 & 0.0778 & 0.0760 & 0.0743 \\
$c$ & 0.4075 & 0.4029 & 0.3982 & 0.3937 & 0.3892 \\
$B$ & 0.0518 & 0.0517 & 0.0516 & 0.0514 & 0.0513 \\
\hline
\end{tabular}

According to Tables 1 - 5, we calculate the elasticity of the endogenous variables with respect to the exogenous variables, which is shown in Table 6. They reflect the sensitivities of the endogenous variables with respect to the exogenous variables. The sign reflects the direction of the effect and the absolute value reflects the strength of effect. Comparing the absolute values of the elasticity gives the following result: each parameter affects capital-labor ratio to different extent, with the basic pension benefit rate the strongest, followed by the population growth rate, and the village subsidy rate and government allowance rate weakest. As to the per capita consumption, the impact of basic pension benefit rate is greatest, followed by the population growth rate, and the village subsidy rate and government allowance rate have little impact. In regard to the pension benefits, the impact of individual contribution rate is greatest, followed by the basic pension benefit rate, local government allowance rate, village subsidy rate and population growth rate.

Table 6 the elasticity of $k, c, B$ on $\tau, \eta, \zeta, j$ and $n$

\begin{tabular}{cccccc}
\hline & $\tau$ & $\eta$ & $\zeta$ & $j$ & $n$ \\
\hline$k$ & 0 & $0.3 \%$ & $0.4 \%$ & $-33.7 \%$ & $-16.4 \%$ \\
$c$ & 0 & $0.1 \%$ & $0.1 \%$ & $-11.4 \%$ & $-8.2 \%$ \\
\multirow{2}{*}{$B$} & $46.2 \%$ & $12.9 \%$ & $16.4 \%$ & $45.1 \%$ & $-1.6 \%$ \\
\hline
\end{tabular}

\section{CONCLUSION}

This paper investigates the rural public pension system in China by developing an exogenous overlapping generations model. It examines the effects of the individual contribution rate, village subsidy rate, local government allowance rate, basic pension benefit rate and population growth rate on the capital-labor ratio, per capita consumption and pension benefits. According to the circumstances in rural areas of China, we estimate the values of relevant parameters, and simulate the effects and the sensitivities of the endogenous variables with respect to the exogenous variables. The differences from the previous studies are that this paper uses an exogenous overlapping generations model to analyze the rural public pension. In addition, except from participants pay pension contributions, villages subsidize and local governments allowance the contributions. 
The results are as follows. Raising the individual contribution rate only increases the pension benefits, and has no effect on the capital-labor ratio and per capita consumption. Both raising the village subsidy rate and local government allowance rate increase the capital-labor ratio, per capita consumption and pension benefits. Raising the basic pension benefit rate decreases the capital-labor ratio and per capita consumption, while increases the pension benefits. A rise in the population growth rate decreases the capital-labor ratio, per capita consumption and pension benefits. The basic pension benefit rate has the strongest effect on the capital-labor ratio, followed in descending order by the population growth rate, local government allowance rate and village subsidy rate. The effects of the four exogenous variables on the per capita consumption rank in the same order. The effect of the individual contribution rate on the pension benefits is the greatest, followed by the basic pension benefit rate, local government allowance rate, village subsidy rate and the population growth rate.

The recovery of world economy is slow after the international financial crisis. China's economic growth rate also falls, and the downside pressure remains. It must rely on expanding domestic demand, including consumption and investment, to maintain a balanced, sustainable and healthy growth of China's economy in the era of post financial crisis. To enhance attraction of the rural public pension system, we should strengthen the incentive mechanism by increasing subsidies at the entrance and pension benefits at the exit of the system. According to the above results, the following statements can be made. In order to increase the capital stock and consumption, it is necessary to reduce the basic pension benefit rate and population growth rate, and raise the local government allowance rate and village subsidy rate. To increase the pension benefits, it is necessary to raise the individual contribution rate, local government allowance rate, village subsidy rate and basic pension benefit rate, while reduce the population growth rate. In accordance with the effects of the five exogenous variables on the endogenous variables and their strengths, it will do more good than harm to raise the individual contribution rate, local government allowance rate and village subsidy rate, maintain the present basic pension benefit rate, and moderately reduce the population growth rate.

Increasing the local government allowance rate and maintaining the present basic pension benefit rate can be fulfilled by adjusting the present fiscal expenditure structure. Local governments can lower the growth rate of additional basic pension benefits or even temporarily do not increase the amount of it. The saved resources can be used to increase the local government allowances to the individual contributions, namely, transform part of allowances from the exit to the entrance. This can increase the local government allowance rate. When the rural residents notice the increased government allowances to pension participants, and become aware of the fact that the more each participant contributes, the more government allowances, they will experience the growth of their own benefits, be more confident about future pension benefits, and then consciously raise contribution level. As a result, the individual contribution rate increases. Rise in the village subsidy rate relies on growth and grandness of village collective economy. Population growth rate control is still relying on the Chinese special population policy. Based on the above results, it is not suitable to relax the population policy greatly.

\section{References}

Barro R.J. 1974. Are government bonds net wealth? Journal of Political Economy 82: 1095-1117.

Blanchard O.J. and Fischer S. 1989. Lectures on Macroeconomics. London: MIT Press.

Diamond P.A. 1965. National debt in a neoclassical growth model. American Economic Review 55: 1126-1150. 
Feldstein, M. 1974. Social security, induced retirement, and aggregate capital accumulation. Journal of Political Economy 82: 905-926.

Gao, F. 2013. Basic Situations of the New-Type Rural and Urban resident Public Pension. Urban and Rural Resident Social Public Pension Seminar proceedings: 1-10.

Kang, C. 2012. Improving the Contribution Rate or Postponing the Retirement Age. Statistical Research 12: 59-68.

Pecchenino R., and Pollard P. 2002. Dependent children and aged parents: funding education and social security in an aging economy. Journal of Macroeconomics 24: 145-169.

Wang, Y., Xu, D., Wang, Z., Zhai, F. 2001. The Implicit Debt, Transition Cost, Reform Forms and the Influence of China's Pension System. Economic Research Journal 5: 3-12.

Yang, Z. 2009. Urban public pension, fertility and endogenous growth in China. Statistical Research 26(5): 77-81.

Yang, Z. 2011. New-style rural old-age insurance and peasant income growth. Beida CCISSR Forum 2011 Annual Conference. In The Twelfth Five-year Plan · New Challenge: Comprehensive Risk Management for Economy and Society, 356-369. Edited by CCISSR. Beijing: Peking University Press.

Zhang J., and Zhang J. 1998. Social security, intergenerational transfers, and endogenous growth. The Canadian Journal of Economics 31: 1225-1241.

Zhang J., Zhang J., and Lee R. 2001. Mortality Decline and Long-Run Economic Growth. Journal of Public Economics 80: 485-507. 